\title{
Melatonin and its metabolites: new findings regarding their production and their radical scavenging actions
}

\author{
Russel J. Reiter ${ }^{1 \bowtie}$, Dun-xian Tan ${ }^{1}$, M. Pilar Terron ${ }^{1}$, Luis J. Flores ${ }^{1}$ and \\ Zbigniew Czarnocki \\ ${ }^{1}$ Department of Cellular and Structural Biology, University of Texas Health Science Center at San Antonio, San \\ Antonio, USA, ${ }^{2}$ Department of Chemistry, University of Warsaw, Warszawa, Poland
}

Received: 16 February, 2007; accepted: 27 February, 2007

available on-line: 09 March, 2007

\begin{abstract}
This review summarizes some of the recent findings concerning the long-held tenet that the enzyme, $\mathrm{N}$-acetyltransferase, which is involved in the production of $\mathrm{N}$-acetylserotonin, the immediate precursor of melatonin, may in fact not always control the quantity of melatonin generated. New evidence from several different laboratories indicates that hydroxyindole-O-methyltransferase, which $\mathrm{O}$-methylates $\mathrm{N}$-acetylserotonin to melatonin may be rate-limiting in some cases. Also, the review makes the point that melatonin's actions are uncommonly widespread in organs due to the fact that it works via membrane receptors, nuclear receptors/binding sites and receptor-independent mechanisms, i.e., the direct scavenging of free radicals. Finally, the review briefly summarizes the actions of melatonin and its metabolites in the detoxification of oxygen and nitrogen-based free radicals and related non-radical products. Via these multiple processes, melatonin is capable of influencing the metabolism of every cell in the organism.
\end{abstract}

Keywords: antioxidant, free radicals, oxidative stress, electron donation, melatonin synthesis

\section{INTRODUCTION}

Melatonin, a secretory product of the vertebrate pineal, is now know to be produced in multiple cells and organs. However, blood melatonin levels are still derived almost exclusively from the pineal gland of mammals. Melatonin generated in other organs seems to be used locally as a paracoid, autocoid, tissue factor and antioxidant (Tan et al., 2003).

The mechanisms controlling the production of melatonin were thought, until recently, to be well defined. As summarized below, however, new evidence indicates that the initial suggestions may have been premature. The other fact that has come to light is that melatonin's actions are much broader than defined several decades ago. Herein, the evidence that melatonin functions via multiple receptors, both membrane and nuclear, and it also scavenges free radicals by processes that require no receptor/binding site.

\section{NEW FINDINGS CONCERNING MELATONIN SYNTHESIS AND ITS MECHANISMS OF ACTION}

Melatonin (N-acetyl-5-methoxytryptamine) was initially isolated from and chemical identified in bovine pineal tissue (Lerner et al., 1959). Subsequently, it was documented that in mammals the nocturnal increase in blood levels of melatonin is almost exclusively a result of its night-time synthesis in and secretion from the pineal gland (Reiter, 1991a). The discovery of the unique nocturnal production of pin-

\footnotetext{
${ }^{\square}$ Corresponding author: Russel J. Reiter, Department of Cellular and Structural Biology, The University of Texas Health Science Center, 7703 Floyd Curl Drive, San Antonio, TX 78229-3900, USA; phone: 210-567-3859; fax: 210-567-6948; e-mail: reiter@uthscsa.edu

Abbreviations: AFMK, $N^{1}$-acetyl- $N^{2}$-formyl-S-methoxykynuramine; AMK, $N^{1}$-acetyl-5-methoxykynuramine; C3-OHM, cyclic 3-hydroxymelatonin; GRd, glutathione reductase; GPx, glutathione peroxidase; HIOMT, hydroxyindole-O-methyltransferase; NAT, N-acetyltransferase; NOS, NO synthetase.
} 
eal melatonin launched an extensive series of studies designed to identify the mechanisms mediating the nighttime surge and also to clarify the enzymes that convert the amino acid, tryptophan, to melatonin.

The results of the earliest investigations in this area suggested that the O-methylation of $\mathrm{N}$-acetyl serotonin (the immediate precursor of melatonin) by the enzyme hydroxyindole-O-methyltransferase (HIOMT) determined the quantity of melatonin produced on a nightly basis (Wurtman \& Axelrod, 1965). The results of subsequent research implied that this may be invalid and a case was made for the enzyme that $\mathrm{N}$-acetylates serotonin, i.e., $\mathrm{N}$-acetyltransferase (NAT), being rate limiting in melatonin production (Klein \& Weller, 1970). This idea persisted for several decades but recent findings have again shifted the emphasis to HIOMT as possibly being responsible for controlling the amount of melatonin produced in the pineal gland at night, at least under some conditions.

In support of HIOMT being the rate limiting enzyme in pineal melatonin production, Ribelayga and colleagues (2000) noted that melatonin levels in the Siberian hamster pineal gland do not correlate with the activity of the serotonin acetylating enzyme but rather levels of the indoleamine fluctuate in synchrony with the activity of HIOMT. Furthermore, it was observed that, also in the same species, stimulation of the pineal gland with $\alpha$ and $\beta$-receptor agonists caused a clear dichotomy between the responses of NAT and melatonin whereas HIOMT activity correlated directly with melatonin (Ceinos et al., 2004). This disconnect between the activity of pineal NAT and the quantity of melatonin in the gland has also been noted in the sheep (Johnston et al., 2004).

Further evidence for NAT not limiting melatonin production has been provided by Liu and Borjigin (2005) who used a genetic mutant rat model, the Long Evens cinnamon (LEC) rat. In this rat strain, a point mutation is associated with low NAT expression and an unstable NAT protein with the actual enzyme activity being reduced by $90 \%$. Despite the apparent large deficiency in NAT activity, the melatonin rhythm in the pineal gland remains essentially unaltered. Moreover, Liu and Borjign (2005) also observed the concentrations of $\mathrm{N}$-acetylserotonin, the product of the $\mathrm{N}$-acetylation of serotonin, had essentially no relationship with melatonin values. Thus, in the presence of unusually high levels of $\mathrm{N}$-acetylserotonin, melatonin values remained depressed. This argues in favor of a mechanism downstream from $\mathrm{N}$-acetylserotonin, i.e., HIOMT activity, being a major determinant of melatonin production. It is also pointed out that in some evolutionarily-low ranked organisms the concentration of $\mathrm{N}$-acetylserotonin may exceed melatonin levels by three orders of magnitude indicating that, in fact, HIOMT is rate limiting in melatonin synthesis in these organisms. Finally, whereas light is certainly the major impeller of the circadian melatonin rhythm, there is also controversial evidence that suggests non-visible electromagnetic radiation may influence the 24-hour rhythm of melatonin (Lerchl et al., 1990). Clearly, what enzyme is most important in the control of melatonin synthesis may have to be re-evaluated. Indeed, the activity of what enzyme actually determines melatonin synthesis may depend on the physiological situation.

\section{MELATONIN RECEPTORS}

The idea that all the actions of melatonin are mediated via specific receptors in cellular membranes has also been modified markedly in recent years. Early studies indicated that the receptors for melatonin were primarily associated with cells in the suprachiasmatic nuclei (SCN) of the anterior hypothalamus (Reppert et al., 1994). While the cells of the SCN do contain large numbers of membrane receptors, they have also been found to be more widely distributed not only in the brain but in many other organs as well (Witt-Enderby et al., 2006). This immediately implies that the actions of melatonin are extremely widespread. In mammals the membrane receptors, classified as MT1 and MT2, are high-affinity and G-proteins coupled (Nosjean et al., 2001; Dubocovich \& Markowska, 2005).

Given that melatonin readily passes through cell membranes, one might expect to find binding sites in the cytosol or nucleus as well. In 1993, Menendez-Pelaez and co-workers noted that, based on immunohistochemical studies, intracellular melatonin concentrations appeared to be usually high in the nuclei of cells. This observation precipitated a search for nuclear binding sites/ receptors which has led to their identification in several tissues (Carrillo-Vico et al., 2003; Naji et al., 2004). A recent review by Tomas-Zapico and Coto-Montes (2005) essentially suggests that all cells that possess membrane melatonin receptors may also contain binding sites for the indoleamine in the nucleus of these cells. In fact, they present a theory as to explain how the membrane and nuclear receptors cooperate in the control of the activity of antioxidative enzymes. This theory still awaits definitive testing.

Besides working via receptors to execute its multiple actions, melatonin is also a direct free radical scavenger as described below. Thus, wherever melatonin is located, either intracellularly and/or extracellularly, it can act merely by detoxifying a radical species via electron donation. What this means is 
that melatonin's action extends to every cell in an organism, or throughout the cell in the case of unicellular organisms.

\section{MELATONIN AS AN ANTIOXIDANT}

Although melatonin was discovered to be a free radical scavenger just over a decade ago (Tan et al., 1993), the data documenting its ability to overcome oxidative stress has accumulated at a rapid pace and it is now abundant (Reiter 2000; Reiter et al., 2001a; Allegra et al., 2003; Hardeland et al., 2003; Hardeland, 2005). The efficacy of melatonin in functioning in this capacity relates to its direct free radical scavenging actions (Allegra et al., 2003; Reiter et al., 2003), its ability to enhance the activities of a variety of antioxidative enzymes (Antolin et al., 1996; Rodriguez et al., 2004; Tomas-Zapico \& Coto-Montes, 2005), its stimulatory actions on the synthesis of another important intracellular antioxidant, glutathione (Winiarska et al., 2006), its efficacy in reducing electron leakage from the mitochondrial electron transport chain (Leon et al., 2005), and its synergistic interactions with other antioxidants (Lopez-Burillo et al., 2003).

Moreover, in recent years it has become apparent that when melatonin scavenges radicals and related reactants, the products that are generated are also free radical scavengers thereby greatly exaggerating the antioxidant potential of melatonin (Hardeland, 2005).

The subsequent paragraphs include a discussion of the metabolites of melatonin that are capable of neutralizing free radicals and non-radical oxygenbased reactants.

\section{ACTIONS OF MELATONIN AND METABOLITES FORMED}

While receptors for melatonin exist on the membranes and possibly in the nucleus of many cells, the direct free radical scavenging actions of melatonin are accomplished without the intervention of a receptor for the indoleamine. Since melatonin readily crosses all morphophysiological barriers and easily penetrates all cells, its actions as a free radical scavenger occur throughout the organism. Also, since all vertebrates and invertebrates produce melatonin (Reiter, 1991b; Hardeland \& Poeggeler, 2003), its actions as a scavenger extend throughout the animal kingdom. Finally, its recent discovery in plants indicates melatonin may reduce oxidative damage in them as well (Hardeland \& Fuhrberg, 1996; Reiter \& Tan, 2002; Hardeland et al., 2005).
Melatonin is also uncommonly effective in neutralizing a number of oxygen-based and nitrogen-based toxic agents, some of which are radicals and some of which are related metabolites (Reiter et al., 2001b; 2003; Allegra et al., 2003). Melatonin was originally shown to detoxify the highly toxic hydroxyl radical $\left({ }^{\circ} \mathrm{OH}\right)$ (Tan et al., 1993). Since this discovery, its scavenging repertoire has been expanded to include hydrogen peroxide $\left(\mathrm{H}_{2} \mathrm{O}_{2}\right)$ (Tan et al., 2000a), hypochlorous acid ( $\mathrm{HOCl})$ (Zavodnik et al., 2004), singlet oxygen $\left({ }^{1} \mathrm{O}_{2}\right)$ (Matuszak et al., 2003), superoxide anion radical $\left(\mathrm{O}_{2}{ }^{-}\right)$, nitric oxide $\left(\mathrm{NO}^{\circ}\right)$ (Ximenes et al., 2005; Aydogan et al., 2006), peroxynitrite anion $\left(\mathrm{ONOO}^{-}\right)$(Reiter et al., 2001a) and others (Hardeland, 2005).

Melatonin possesses an electron-rich aromatic indole ring and functions as an electron donor, thereby reducing and repairing electrophilic radicals (Martinez et al., 2005). Melatonin seems not to undergo redox cycling and is considered a suicidal or terminal antioxidant (Tan et al., 2000b). Cyclic voltametry indicates that melatonin donates an electron at a potential of $715 \mathrm{mV}$. In doing so, melatonin becomes irreversibly oxidized and is not recycled.

While melatonin scavenges a number of reactants, as enumerated above, the most obvious finding in the oxidation chemistry of melatonin is the scavenging of the ${ }^{\circ} \mathrm{OH}$ (Tan et al., 1993; Hardeland \& Fuhrberg, 1996; Poeggeler et al., 1996). As such, melatonin is more effective than most of its naturally occurring structural analogues (Tan et al., 1993; Poeggeler et al., 1995; 2002).

This suggests that the substituents of melatonin's indole moiety strongly influence is reactivity and selectivity. The rate constant has been calculated for the interaction of melatonin with the ${ }^{\circ} \mathrm{OH}$ and, depending on the method used for measurement, it ranges from 1.2 to $7.5 \times 10^{10} \mathrm{M}^{-1} \mathrm{~s}^{-1}$ (Matuszek et al., 1997; Stascia et al., 1998a; 1998b; Chyan et al., 1999; Mahal et al., 1999).

An interaction of melatonin with the ${ }^{\bullet} \mathrm{OH}$ was first documented by Tan et al. (1993) slightly over a decade ago. In this report the authors used electron spin resonance (ESR) spectroscopy to confirm melatonin's scavenging action. Also of importance in this report was that the scavenging of two ${ }^{\circ} \mathrm{OH}$ by melatonin generated the metabolite cyclic 3-hydroxymelatonin $(\mathrm{C} 3-\mathrm{OHM})$. As it turns out, $\mathrm{C} 3-\mathrm{OHM}$ is an intermediate metabolite since it undergoes oxidation resulting in the formation of $N^{1}$-acetyl- $N^{2}$-formyl-5methoxykynuramine (AFMK) (Fig. 1). Melatonin's ability to neutralize the precursor of the ${ }^{\circ} \mathrm{OH}$, i.e., $\mathrm{H}_{2} \mathrm{O}_{2}$, has also been documented (Tan et al., 2000b). The reaction of melatonin with $\mathrm{H}_{2} \mathrm{O}_{2}$ leads to the oxidative cleavage of the indole ring of melatonin to produce AFMK; this product has been identified by electrospray ionization (ESI) mass spectrometry 


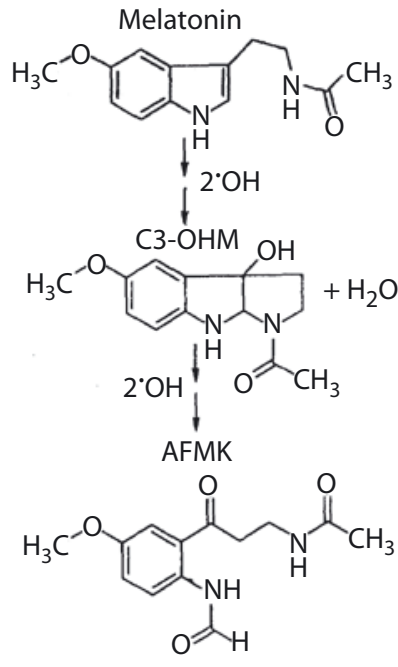

Figure 1. Hypothesized mechanism for the formation of cyclic 3-hydroxymelatonin (C3-OHM) during the oxidation of melatonin by hydroxyl radicals $\left({ }^{\circ} \mathrm{OH}\right)$.

Once $\mathrm{C} 3-\mathrm{OHM}$ is formed it is further oxidized to $N^{1}$ acetyl- $N^{2}$-formyl-S-methoxykynuramine (AFMK).

(MS), proton nuclear magnetic resonance $\left({ }^{1} \mathrm{H}-\mathrm{NMR}\right)$ and carbon nuclear magnetic resonance $\left({ }^{12} \mathrm{C}-\mathrm{NMR}\right)$ (Tan et al., 2000b; Carampin et al., 2003). Tan and colleagues (2001b; 2007) have proposed that AFMK could be generated via a dioxetane intermediate or through the standard alkene epoxidation reaction followed by hydrolysis to the diol, which is then oxidized to AMFK. Like melatonin, AFMK is an effective free radical scavenger (Hardeland 2005; Onuki et al., 2005; Tan et al., 2007). These two schemes are summarized in Fig. 2.

The photosensitization of endogenous molecules and also lipid peroxidation within cells can generate ${ }^{1} \mathrm{O}_{2}$ (Miyamoto et al., 2003). ${ }^{1} \mathrm{O}_{2}$ is highly

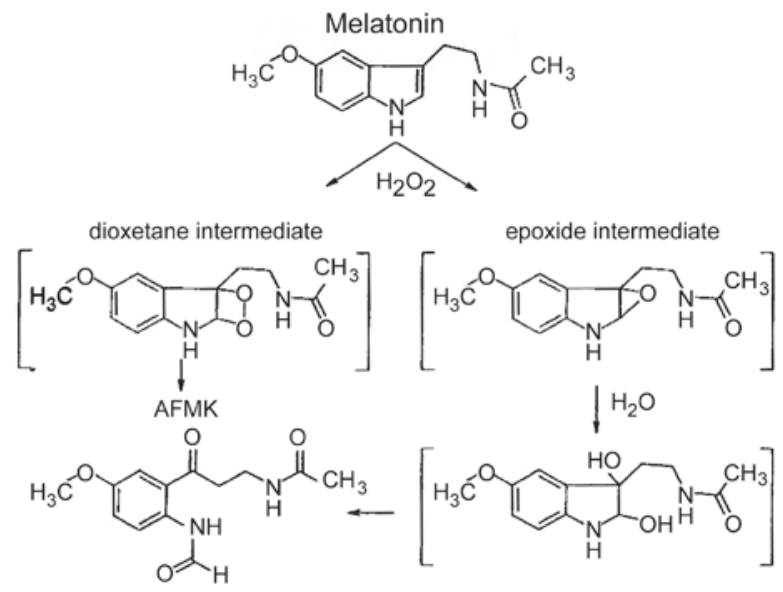

Figure 2. Hypothesized mechanism for the formation for $N^{1}$-acetyl- $N^{2}$-formyl-S-methoxykynuramine (AFMK) during the oxidation of melatonin by hydrogen peroxide $\left(\mathrm{H}_{2} \mathrm{O}_{2}\right)$.

Two potential pathways are proposed; one invloves a dioxetane intermediate while the other involves standard alkalene epioxidation. reactive toward electron-rich molecules and it is capable of damaging biomolecules (Cavalvante et al., 2002). The product formed when melatonin is oxidized by ${ }^{1} \mathrm{O}_{2}$ is AFMK (Almeida et al., 2003). Immune responsive cells are also capable of oxidizing melatonin; this reaction involves myloperoxidase and also produces AFMK (Silva et al., 2000; Ximenes et al., 2001).

Melatonin has a number of effects at the mitochondrial level that improve the well being of cells and prevents normal cells from undergoing apoptosis (Acuna-Castroviejo et al., 2002; Leon et al., 2005). Thus, melatonin influences both the electron transport chain (ETC) and oxidative phosphorylation by increasing electron transport and ATP production in normal cells. It also counteracts damage resulting from the exposure of mitochondria to tert-butyl hydroperoxide, and restores reduced glutathione levels and enhances the production of ATP. These actions of melatonin may not relate to its antioxidant activities since the indoleamine specifically interacts with complex I and complex IV of the ETC to achieve these changes (Acuna-Castroviejo et al., 2003). Melatonin also rescues normal cells from apoptosis but this response, at least in some cases, is dependent upon the free radical scavenging activity of the indoleamine (Jou et al., 2004). Interestingly, in tumors melatonin exaggerates the death of cells via apoptosis (Sainz et al., 2003).

In addition to melatonin's activities as a direct free radical scavenger, it also reportedly enhances organisms to defend against oxidative stress by promoting enzymes that metabolize radicals and their products to innocuous agents (Fig. 3). These indirect antioxidative effects of melatonin may well be mediated via membrane and/or nuclear receptors. Examples include the often reported stimulation of glutathione peroxidase (GPx) (Barlow-Walden et al., 1995; Kotler et al., 1998; Reiter et al., 2000; Okatani et al., 2002; Rodriquez et al., 2004; Tomas-Zapico \& Coto-Montes, 2005), which converts hydroperoxides, including $\mathrm{H}_{2} \mathrm{O}_{2}$, to water and oxygen while oxidizing GSH. Once the oxidized form of glutathione, i.e., GSSG, is formed it is recycled to GSH by glutathione reductase (GRd), another enzyme whose activity is enhanced by melatonin (Reiter et al., 1998; Liu $\& \mathrm{Ng}, 2000$ ). Likewise, the superoxide dismutases (Rodriguez et al., 2004; Tomas-Zapico \& Coto-Montes, 2005) (SODs, including $\mathrm{Cu}, \mathrm{Zn}-\mathrm{SOD}$ and $\mathrm{Mn}-$ SOD), which enzymatic dismutate $\mathrm{O}_{2}{ }^{--}$to $\mathrm{H}_{2} \mathrm{O}_{2}$, are also under the stimulatory influence of melatonin. Finally, one report claimed that melatonin stimulated glucose-6-phosphate dehydrogenase activity (Hardeland, 2005); this would be important in providing reducing equivalents, i.e., $\mathrm{NADPH}$, for the action of GRd. Less commonly, melatonin has been reported to promote catalase (CAT) activity (Reiter $e t$ 


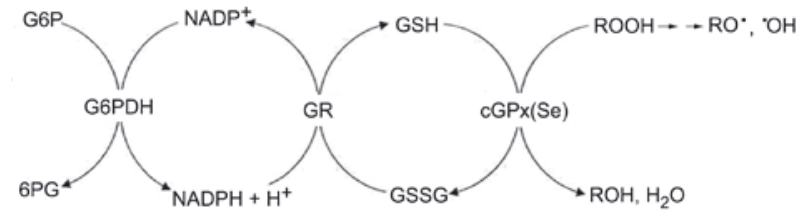

Figure 3. Metabolic recycling of glutathione by glutathione peroxidase $(\mathrm{cGPx}(\mathrm{Se}))$ and glutathione reductase (GR).

The activity of GR requires NADPH which is supplied by the activity of the enzyme, glucose-6-phosphate dehydrogenase $(\mathrm{G} 6 \mathrm{PDH})$. Melatonin reportedly stimulates the activity of GPx, GR and G6PDH. G6P, glucose-6-phosphate; 6PG, 6-phosphogluconate; $\mathrm{RO}^{\bullet}$, alkoxyl radical; ${ }^{\circ} \mathrm{OH}$, hydroxyl radical; $\mathrm{ROOH}$, hydroperoxide.

al., 2001b; Rodriguez et al., 2004; Gomez et al., 2005; Tomas-Zapico \& Coto-Montes, 2005).

The stimulatory actions of melatonin on these antioxidative enzymes have been observed in a variety of species and in many different tissues. Also, both physiological levels (Pablos et al., 1998; Mayo et al., 2002) and pharmacological doses of melatonin seem capable of promoting antioxidant enzyme activities. Nevertheless, whereas stimulatory effects of melatonin have repeatedly been described, not every publication found an augmentation of antioxidative enzyme activities after melatonin treatment (Balkan et al., 2004; Ohta et al., 2004). These apparent contrary findings could be a result of the unique features of the tissue investigated or a consequence of the timing of tissue collection after melatonin administration.

GSH is an important intracellular antioxidant which is typically in high concentrations within cells. Its production is controlled by the enzyme $\gamma$ glutamylcysteine synthase. In addition to the evidence showing that melatonin commonly preserves GSH levels when cells are under oxidative attack, two studies also report a stimulation of the activity of its rate limiting enzyme (Urata et al., 1999; Winiarska et al., 2006). How essential the promotion of GSH synthesis is in terms of melatonin's ability to limit oxidative stress has not been determined.

The down regulation of several prooxidant enzymes is also a reported function of melatonin. In particular, 5- and 12-lipoxygenases (Manev et al., 1998; Uz \& Manev, 1998; Zhang et al., 1999) as well as NO synthase (Pozo et al., 1994; Bettahi et al., 1996; Hardeland et al., 2003; Escames et al., 2006) respond to melatonin in a negative manner. The almost universal observation of a down regulation of NOS by melatonin would markedly curtail the generation of the highly reactive and toxic $\mathrm{ONOO}^{-}$; this down regulation could contribute significantly to melatonin's prevention of oxidative stress. Furthermore, the negative actions of melatonin on NOS would stymie the formation of radical prod- ucts that derive from $\mathrm{ONOO}^{-}$, i.e., ${ }^{-} \mathrm{NO}_{2}, \mathrm{CO}_{3}{ }^{--}$and $\cdot \mathrm{OH}$.

Of additional interest regarding melatonin, is its reported binding to quinone reductase 2 (Nosjean et al., 2000; 2001; Witt-Enderby et al., 2003). This enzyme, which is considered a melatonin receptor, is important in the detoxification of prooxidant quinones. This function of melatonin should be more thoroughly examined relative to the ability of the indoleamine to reduce levels of oxidative stress that are a consequence of toxic quinones.

A final feature of melatonin that should be considered in its function as a ubiquitously acting protector against oxidative damage is melatonin's synergistic actions with the some classic antioxidants, e.g., vitamin $\mathrm{C}$ and $\mathrm{E}$. When antioxidant treatment includes melatonin in combination with either vitamin $\mathrm{C}$ or $\mathrm{E}$, the protective effect is better than the combined actions of both detoxifying agents, i.e., they synergize to produce a greater benefit (Gitto et al., 2001; Lopez-Burillo et al., 2003).

Melatonin has also frequently been compared with vitamins $C$ and $E$ in vivo in terms of their degrees of antioxidative protection. When equal doses of these antioxidants are given, melatonin has consistently performed better than either of these vitamins (Hsu et al., 2000; Montilla et al., 2001; MartinezCruz et al., 2002). Often vitamins $C$ and $E$ are given in larger doses than melatonin and yet their ability to reduce oxidative stress is less than that of a lower dose of melatonin.

\section{METABOLITES OF MELATONIN IN ANTIOXIDATIVE PROTECTION}

As seen in Fig. 1, when the melatonin metabolite $\mathrm{C} 3-\mathrm{OHM}$ is formed, it is also believed to scavenge two ${ }^{\circ} \mathrm{OH}$ to generate AFMK. In studies conducted in vitro, C3-OHM has been found to be a powerful protector against oxidative stress, at least in regard to reducing lipid peroxidation (D.X. Tan, R.J. Reiter, unpublished observation). In general, this metabolite has rarely been tested for its antioxidant activity; one factor that likely accounts for this paucity of studies relates to the fact that this molecule is not commercially available.

Tan and co-workers (2001) have shown that AFMK is also capable of donating electrons to detoxify radical species. With the aid of cyclic voltametry, this group showed that AFMK donates two electrons at potentials of $456 \mathrm{mV}$ and $668 \mathrm{mV}$, respectively. Thus, like it parent molecule, its functions as a reducing agent. This was further documented when it was shown that AFMK preserves the integrity of DNA that is otherwise damaged when it is exposed to oxidizing agents. Likewise, the peroxida- 
tion of lipids in hepatic homogenates is inhibited in the presence of AFMK. In reference to both oxidantinduced DNA and lipid damage, the protective actions of AFMK are concentration dependent. Finally, in cultured hippocampal neurons, AFMK eliminated the toxicity of hydrogen peroxide, glutamate and amyloid- $\beta$ 25-35.

5-Aminolevulinic acid (ALA) accumulates in humans under conditions of lead poisoning, hereditary tyrosinemia and acute intermittent porphyria. ALA has significant oxidative potential and often damages DNA. The ability of AFMK to reduce DNA damage caused by $\mathrm{ALA} / \mathrm{Fe}^{2+}$ in vitro was assessed by Onuki et al. (2005). Damage was estimated using DNA plasmid breaks and the detection of 8-oxo-7,8-dihydro-2-deoxyguanosine using HPLC. AFMK, in a dose-dependent manner, protected against free radical damage. In this study, AFMK was compared with melatonin, quercetin and resveratrol in terms of their relative protective actions. The efficacy of these antioxidants in resisting free radical damage depended on the model system used. AMK may even be a better free radical scavenger than is AFMK. This molecule if formed from AFMK via pyrrole ring cleavage. The scavenging action of AMK against the $\cdot \mathrm{OH}$ was documented by competition with ABTS cation radicals in a Fenton reaction system at $\mathrm{pH} 5.0$ and by competition with dimethylsulfoxide (DMSO) in a hemin-catalyzed $\mathrm{H}_{2} \mathrm{O}_{2}$ system at pH 8.0 (Ressmeyer et al., 2003). The physiological protection against oxidative damage by AMK was demonstrated in an oxidative protein destruction assay where AMK proved to be highly protective. When AMK functions as an antioxidant in vivo the products formed may be 3-acetamidomethyl6-methoxycinnolinone and 3-nitro-AMK (Guenther et al., 2005).

There are currently no studies related to the ability of any of the melatonin metabolites mentioned above to stimulate the activity of antioxidative enzymes. However, AMK has been shown to inhibit the prooxidative enzyme, NOS (Leon et al., 2006); both in vitro and in vivo studies were performed. AMK, but not AFMK, inhibited neuronal NOS activity in a dose-response manner in vitro. A $20 \%$ inhibition of NOS was achieved at a concentration of $10^{-11} \mathrm{M}$ AMK; in contrast, melatonin caused a $20 \%$ reduction in enzyme activity at $10^{-10} \mathrm{M}$. AMK was shown to reduce neuronal NOS via a non-competitive mechanism by binding with $\mathrm{Ca}^{2+}$-calmodulin. In vivo, the potency of AMK in inhibiting striatal NOS activity was greater than that of melatonin. Thus, a $25 \%$ reduction in striatal NOS activity was seen in rats given $10 \mathrm{mg} / \mathrm{kg}$ AMK while it required a dose of $20 \mathrm{mg} / \mathrm{kg}$ melatonin to achieve the same degree of inhibition. One clear implication of these findings is that AMK, rather than melatonin, may account for the inhibitory effect of the later molecule on NO synthesis.

As noted above, the formation of AMK during the catabolism of melatonin seems not to end with this molecule. Rather AMK, in the presence of NO donors, forms $N^{1}$-acetyl-5-methoxy-3-nitrokynuramine (AMNK) while in the presence of peroxynitrite AMK is converted to 3-acetoamidomethyl-6-methoxycinnolinone (AMMC) (Guenther et al., 2005). These molecules were formed in a pure chemical system and whether they would be produced in vivo remains unknown. However, the authors of the report feel it is likely that they are formed in organisms, particularly AMMC. These findings suggest that the catabolism of melatonin does not end at the level of AMK and additional products may be generated in situations where both reactive oxygen (to produce AFMK and AMK) and reactive nitrogen species (to form AMNK and AMMC) are elevated. The observation of Guenther and co-workers (2005) extends the cascade of reactions whereby melatonin protects against oxidative/nitrosative stress.

\section{CONCLUDING REMARKS}

This brief review summarizes some of the vast literature related to the antioxidative actions of the indole, melatonin. Melatonin is an uncommonly diverse free radical scavenger that directly interacts with a variety of oxygen and nitrogen-based radicals and related reactants. Also, although not thoroughly discussed in this report, melatonin protects against molecular damage seemingly in all regions of the cell, i.e., in both the lipid and aqueous compartments. Furthermore, it protects against lipid peroxidation, protein mutilation and against both mitochondrial and nuclear DNA damage by radicals and their toxic products. These direct radical scavenging actions of melatonin are receptor-independent processes.

In reference to the ability of melatonin as well as its metabolites to directly neutralize free radicals is the issue of their respective intracellular concentrations. Relative to GSH, for example, the concentrations of melatonin, C3-OHM, AFMK and AMK seem to be low. If so, to function as effective scavengers in the presence of higher concentrations of GSH, they must have some positional advantage within the cell. How, or whether, this occurs remains to be established.

Many cells, however, contain specific receptors for the melatonin molecule. The stimulation of antioxidative enzymes, i.e., SODs, GPx, GRd and catalase, may well involve an interaction of melatonin with these conventional receptors, both mem- 
brane and nuclear. The membrane receptors for melatonin are well characterized; however, nuclear binding sites/receptors also exist for this indole and may be involved in the signal transduction mechanisms whereby melatonin promotes the activities of antioxidative enzymes.

Finally, what is becoming increasing apparent is that metabolites that are formed when melatonin is oxidized, e.g., C3-OHM, AFMK and AMK, contribute to the reducing potential of melatonin. Indeed, at this point it is not possible to determine whether the protective actions of melatonin are due to melatonin per se, to its metabolites, to its ability to stimulate antioxidative enzymes, or due to its action in inhibiting prooxidative enzymes. It is likely that each of these processes will prove to be important.

\section{REFERENCES}

Acuna-Castroviejo D, Escames G, Carazo A, Leon J, Khaldy H, Reiter RJ (2002) Melatonin, mitochondria homeostasis and mitochondrial-related diseases. Curr Top Med Chem 2: 133-152.

Acuna-Castroviejo D, Escames G, Leon J, Carozo A, Khaldy $H$ (2003) Mitochondrial regulation by melatonin and its metabolites. Adv Exp Med Biol 527: 549-557.

Allegra M, Reiter RJ, Tan DX, Gentile C, Tesoriere L, Livrea MA (2003) The chemistry of melatonin interaction with reactive species. J Pineal Res 34: 1-10.

Almeida EA, Martinez GR, Klitzke GF, Medeiros MHG, Di Mascio P (2003) Oxidation of melatonin by singlet molecular oxygen $\left(\mathrm{O}_{2}\left({ }^{1} \Delta_{\mathrm{g}}\right)\right.$ produces N1-acetyl-N2-formyl5-methoxykynuramine. J Pineal Res 35: 131-137.

Antolin I, Rodriguez C, Sainz RM, Mayo J, Uria H, Kotler ML, Rodriguez-Colunga MJ, Tolivia D, MenendezPelaez A (1996) Neurohormone melatonin prevents cell damage: effect on gene expression for antioxidant enzymes. FASEB J 10: 882-890.

Aydogen S, Yerer MB, Goktas A (2006) Melatonin and nitric oxide. J Endocrinol Invest 29: 281-287.

Balkan J, Sever G, Cevikbas U, Keyer-Uysal M, Uysal M (2004) Melatonin improved the disturbances in hepatic prooxidant and antioxidant balance and hepatotoxicity induced by a high cholesterol diet in $\mathrm{C} 57 \mathrm{Bl} / 6 \mathrm{~J}$ mice. Int J Vitam Nutr Res 74: 349-354.

Barlow-Walden LR, Reiter RJ, Abe M, Pablos M, Menendez-Pelaez A, Chen LD, Poeggeler B (1995) Melatonin stimulates brain glutathione peroxidase activity. Neurochem Int 26: 497-502.

Bettahi I, Pozo D, Osuna C, Reiter RJ, Acuna-Castroviejo D, Guerrero JM (1996) Melatonin inhibits nitric oxide synthase activity in rat hypothalamus. J Pineal Res 20: 205-210.

Carampin P, Rosan S, Dalzoppo D, Zagotto G, Zatta P (2003) Some biochemical properties of melatonin and the characterization of the relevant metabolite arising from its interaction with $\mathrm{H}_{2} \mathrm{O}_{2}$. J Pineal Res 34: 134-142.

Carrillo-Vico A, Garcia-Perganeda A, Naji L, Calvo JR, Romero MP, Guerrero JM (2003) Expression of membrane and nuclear melatonin receptor mRNA and protein in mouse immune system. Cell Mol Life Sci 60: 2272-2278.

Cavalvante AK, Martinez GR, Di Mascio P, Menck GFM, Agnez-Lima LF (2002) Cytotoxicity and mitogenesis induced by singlet oxygen in wild type and DNA repair deficient. Escherichia coli strains. DNA Repair 1: 1051-1056.

Ceinos RM, Chansard M, Revel F, Calgari C, Miquez JM, Simmonneaux V (2004) Analysis of adrenergic regulation of melatonin synthesis in Siberian hamster pineal emphasizes the role of HIOMT. Neurosignals 13: 308317.

Chyan YJ, Poeggeler B, Omar RA, Chain DG, Frangione B, Ghiso J, Pappolla MA (1999) Potent neuroprotective properties against the Alzheimer beta-amyloid by an endogenous melatonin-related indole structure, indole3-propionic acid. J Biol Chem 273: 21937-21942.

Dubocovich M, Markowska M (2005) Functional MT1 and MT2 melatonin receptors in mammals. Endocrine 27: 101-110.

Escames G, Lopez LC, Tapias V, Utrilla P, Reiter RJ, Hitos AB, Leon J, Rodriguez MI, Acuna-Castroviejo D (2006) Melatonin counteracts inducible mitochondrial nitric oxide synthase-dependent mitochondrial dysfunction in skeletal muscle of septic mice. J Pineal Res 40: 71-78.

Gitto E, Tan DX, Reiter RJ, Karbownik M, Manchester LC, Cuzzocrea S, Fulia F, Barberi I (2001) Individual and synergistic antioxidative actions of melatonin with vitamin E, vitamin C, glutathione and desferrioxamine in rat liver homogenates. J Pharm Pharmacol 53: 13931401.

Gomez M, Esparza JL, Nogues MR, Giralt M, Cabre M, Domingo JL (2005) Pro-oxidant activity of aluminum in the rat hippocampus: gene expression of antioxidant enzymes after melatonin administration. Free Radic Biol Med 38: 104-111.

Guenther AL, Schmidt SI, Laatsch H, Fotso S, Ness H, Ressmeyer AR (2005) Reactions of the melatonin metabolite AMK ( $\mathrm{N}^{1}$-acetyl-5-methoxykynuramine) with reactive nitrogen species: formation of novel compounds, acetamidomethyl-6-methoxycinnolinone and 3-nitro-AMK. J Pineal Res 39: 251-260.

Hardeland R (2005) Antioxidant protection by melatonin. Endocrine 27: 119-130.

Hardeland R, Fuhrberg B (1996) Ubiquitous melatonin - presence and effects in unicells, plants and animals. Trends Comp Biochem 2: 25-45.

Hardeland R, Poeggeler B (2003) Non-vertebrate melatonin. J Pineal Res 34: 233-241.

Hardeland R, Coto-Montes A, Poeggeler B (2003) Circadian rhythms, oxidative stress, and antioxidative defenses mechanisms. Chronobiol Int 20: 921-926.

Hardeland R, Pandi Perumal SR (2005) Melatonin, a potent agent in antioxidative defense: actions as a natural food contaminant, gastrointestinal factor, drug and prodrug. Nutr Metab 2: 22-31.

Hsu CH, Han BC, Liu MY, Yeh CY, Casida JE (2000) Phosphine-induced oxidative damage in rats: attenuation by melatonin. Free Radic Biol Med 28: 636-642.

Johnston JD, Bashforth R, Diack A, Anderson H, Lincoln GA, Hazelerigg DC (2004) Rhythmic melatonin secretion does not correlate with the expression of arylalkylamine $\mathrm{N}$-acetyltransferase, inducible cyclic AMP early repressor period 1 or cytochrome 1 mRNA in the sheep pineal. Neuroscience 124: 789-795.

Jou MJ, Peng TI, Reiter RJ, Jou SB, Wu HY, Wen ST (2004) Visualization of the antioxidative effects of melatonin at the mitochondrial level during oxidative-stress apoptosis of rat brain astrocytes. J Pineal Res 37: 55-70.

Klein DC, Weller JL (1970) Indole metabolism in the pineal gland: a circadian rhythm in $\mathrm{N}$-acetyltransferase. Science 169: 1093-1095. 
Kotler M, Rodriguez C, Sainz RM, Antolin I, MenendezPelaez A (1998) Melatonin increases gene expression for antioxidant enzymes in rat brain cortex. J Pineal Res 24: 83-89.

Leon J, Acuna-Castroviejo D, Escames G, Tan DX, Reiter RJ (2005) Melatonin mitigates mitochondrial malfunction. J Pineal Res 38: 1-9.

Leon J, Escames G, Rodriquez MI, Lopez LC, Tapias V, Entrena A, Camacho E, Carrion MD, Gallo MA, Espinosa A, Tan DX, Reiter RJ, Acuna-Castroviejo D (2006) Inhibition of neuronal nitric oxide synthase activity by $\mathrm{N}^{1}$-acetyl-5-methoxykynuramine, a brain metabolite of melatonin. J Neurochem 98: 2023-2033.

Lerchl A, Nonaka KD, Stokkan KA, Reiter RJ (1990) Marked rapid alterations in nocturnal serotonin metabolism in mice and rats exposed to weak intermittent magnetic fields. Biochem Biophys Res Commun 169: 102-108.

Lerner AB, Case JD, Heinzelmann RV (1959) Structure of melatonin. J Am Chem Soc 81: 6084-6085.

Liu F, Ng TB (2000) Effect of pineal indoles on activities of the antioxidant defense enzymes superoxide dismutase, catalase and glutathione reductase, and levels of reduced and oxidized glutathione in rat tissues. Biochem Cell Biol 78: 447-453.

Liu T, Borjigin J (2005) N-acetyltransferase is not the ratelimiting enzyme of melatonin synthesis at night. J Pineal Res 39: 91-96.

Lopez-Burillo S, Tan DX, Mayo JC, Sainz RM, Reiter RJ (2003) Melatonin, xanthurenic acid resveratrol, EGCG, vitamin $C$ and alpha-lipoic acid differentially reduce oxidative DNA damage induced by Fenton reagents; a study of their individual and synergistic actions. J Pineal Res 34: 269-277.

Mahal HS, Sharman HS, Mukherjee T (1999) Antioxidant properties of melatonin: a pulse radiolysis study. Free Radic Biol Med 26: 557-565.

Manev H, Uz T, Ou T (1998) Early upregulation of hippocampal 5-lipoxygense following systemic administration of kianate. Restor Neural Neurosci 12: 81-85.

Martinez GR, Almeida EA, Klitzke CF, Onuki J, Prado FM, Medeiros MH, Di Mascio P (2005) Measurement of melatonin and its metabolites: importance for the evaluation of their biological roles. Endocrine 27: 111-118.

Martinez-Cruz F, Pozo D, Osuna C, Espinar A, Merchante C, Guerrero JM (2002) Oxidative stress induced by phenylketonuria in the rat: prevention by melatonin, vitamin E and vitamin C. J Neurosci Res 69: 550-558.

Matuszak Z, Reszka K, Chignell CF (1997) Reaction of melatonin and related indoles with hydroxyl radicals: ERP and spin trapping investigations. Free Radic Biol Med 23: 367-372.

Matuszak Z, Bilska MA, Reszka KJ, Chignell CF, Bilski $P$ (2003) Interaction of singlet molecular oxygen with melatonin and related indoles. Photochem Photobiol 78: 449-455.

Mayo JC, Sainz RM, Antolin I, Herrera F, Martin V, Rodriguez C (2002) Melatonin regulation of antioxidant enzyme expression. Cell Mol Life Sci 59: 1706-1713.

Menendez-Pelaez A, Poeggeler B, Reiter RJ, Barlow-Walden LR, Pablos MI, Tan DX (1993) Nuclear localization of melatonin in different mammalian tissues: immunological and radioimmunoassay evidence. J Cell Biochem 53: 373-382.

Miyamoto S, Martinez GR, Medeiros MHG, Di Mascio P (2003) Singlet molecular oxygen generated from lipid hydroperoxides by the Russell mechanism: studies using 18(O)-labeled linoleic acid hydroperoxide and monomol light emission measurements. I Am Chem Soc 125: 6172-6179.

Montilla P, Cruz A, Padillo F, Tunez I, Gascon F, Munoz MC, Gomez M, Pera C (2001) Melatonin versus vitamin $\mathrm{E}$ as protective treatment against oxidative stress after extra-hepatic bile duct ligation in rats. J Pineal Res 31: 138-144.

Naji L, Carrillo-Vico A, Guerrero JM, Calvo JR (2004) Expression of membrane and nuclear melatonin receptors in mouse peripheral organs. Life Sci 74: 2227-2236.

Nosjean O, Ferro M, Coge F, Beauverger P, Henlin JM, Lefoulon F, Fauchere JL, Delagrange P, Canet E, Boutin JA (2000) Identification of the melatonin-binding site MT3 as the quinone reductase 2. J Biol Chem 275: 31311-31317

Nosjean O, Nicolas JP, Klupsch F, Delagrange P, Canet E, Boutin JA (2001) Comparative pharmacological studies of melatonin receptors: MT1, MT2 and MT3-QR2: tissue distribution of MT3/QR2. Biochem Pharmacol 61: 1369-1379.

Ohta Y, Kongo-Nishimura M, Matsura T, Yamada K, Kitagawa A, Kishikawa T (2004) Melatonin prevents disruption of hepatic reactive oxygen species metabolism in rats treated with carbon tetrachloride. J Pineal Res 36: 10-17.

Okatani Y, Walsatsuki A, Reiter RJ, Miyahara Y (2002) Melatonin reduces oxidative damage of neural lipids and proteins in senescence-accelerated mouse. Neurobiol Aging 23: 639-644.

Onuki J, Almeida EA, Medeiros MHG, Mascio PD (2005) Inhibition of 5-aminolevulinic acid-induced DNA damage by melatonin, $\mathrm{N}^{1}$-acetyl- $\mathrm{N}^{2}$-formyl-5-methoxykynuramine, quercetin or resveratrol. J Pineal Res 38: 107-115.

Pablos MI, Reiter RJ, Ortiz GG, Guerrero JM, Agapito MT, Chuang JI, Sewerynek E (1998) Rhythms of glutathione peroxidase and glutathione reductase in brain of chick and their inhibition by light. Neurochem Int 32: 69-75.

Poeggeler B, Reiter RJ, Hardeland R, Sewerynek E, Melchiorri D, Barlow-Walden LR (1995) Melatonin, a mediator of electron transfer and repair reactions acts synergistically with the chain breaking antioxidants ascorbate trolox and glutathione. Neuroendocrinol Lett 17: 87-92.

Poeggeler B, Reiter RJ, Hardeland R, Tan DX, BarlowWalden LR (1996) Melatonin and structurally-related endogenous indoles act as potent electron donors and radical scavengers in vitro. Redox Repo 2: 179-184.

Poeggeler B, Thuermann S, Dose A, Schoenke M, Burkhardt S, Hardeland R (2002) Melatonin's unique radical scavenging properties role of its functional substituents as revealed by a comparison with its structural analogs. J Pineal Res 33: 20-30.

Pozo D, Reiter RJ, Calvo JR, Guerrero JM (1994) Physiological concentrations of melatonin inhibits nitric oxide synthase in rat cerebellum. Life Sci 55: PL455-460.

Reiter RJ (1991a) Melatonin: The chemical expression of darkness. Mol Cell Endocrinol 79: C153-C158.

Reiter RJ (1991b) Pineal melatonin: cell biology of its synthesis and of its physiological interactions. Endocrine Rev 12: 151-180.

Reiter RJ (2000) Melatonin: lowering the high price of free radicals. New Physiol Sci 15: 246-250.

Reiter RJ, Tan DX (2002) Melatonin: an antioxidant in edible plants. Ann N Y Acad Sci 957: 341-344.

Reiter RJ, Garcia JJ, Pie J (1998) Oxidative toxicity in models of neurodegeneration: responses to melatonin. Restor Neurol Neurosci 12: 135-142. 
Reiter RJ, Tan DX, Osuna C, Gitto E (2000) Actions of melatonin in the reduction of oxidative stress: a review. $J$ Biomed Sci 7: 444-458.

Reiter RJ, Tan DX, Manchester LC, Qi W (2001a) Biochemical reactivity of melatonin with reactive oxygen and nitrogen species. Cell Biochem Physiol 34: 237-256.

Reiter RJ, Acuna-Castroviejo D, Tan DX, Burkhardt S (2001b) Free radical-mediated molecular damage: mechanisms for the protective actions of melatonin in the central nervous system. Ann N Y Acad Sci 939: 200-215.

Reiter RJ, Tan DX, Mayo JC, Sainz RM, Leon J, Czarnocki Z (2003) Melatonin as an antioxidant: biochemical mechanisms and pathophysiological implications. Acta Biochim Polon 50: 1129-1146.

Reppert SM, Weaver DR, Ebisawa T (1994) Cloning and characterization of mammalian melatonin receptor that mediates reproductive and circadian responses. Neuron 13: $1177-1185$.

Ressmeyer AR, Mayo JC, Zelosko V, Sainz RM, Tan DX, Poeggeler B, Antolin I, Zsizsik BK, Reiter RJ, Hardeland R (2003) Antioxidant properties of the melatonin metabolite $\mathrm{N}^{1}$-acetyl-5-methoxykynuramine (AMK); scavenging of free radicals and prevention of protein oxidation. Redox Rep 8: 205-213.

Ribelayga C, Pevet P, Simmonneaux V (2000) HIOMT drives the photoperiodic change in the amplitude of the melatonin peak in the Siberian hamster. Am J Physiol 278: R1339-R1345.

Rodriguez C, Mayo JC, Sainz RM, Antolin I, Herrera F, Martin V, Reiter RJ (2004) Regulation of antioxidant enzymes: a significant role for melatonin. J Pineal Res 36: 1-9.

Sainz RM, Mayo JC, Rodriguez C, Tan DX, Lopez-Burillo S, Reiter RJ (2003) Melatonin and cell death: differential actions on apoptosis in normal and cancer cells. Cell Mol Life Sci 60: 1407-1426.

Silva SO, Ximenes VF, Catalani LH, Campa A (2000) Myelopeoxidase-catalyzed oxidation of melatonin by activated neutrophils. Biochem Biophys Res Commun 282: 380-386.

Stasica P, Ulanski P, Rosiak JM (1998a) Melatonin as a hydroxyl radical scavenger. J Pineal Res 25: 65-66.

Stasica P, Ulanski P, Rosiak JM (1998b) Reaction of melatonin with radicals in deoxygenated aqueous solutions. J Radioanal Nucl Chem 232: 107-113.

Tan DX, Chen LD, Poeggeler B, Manchester LC, Reiter RJ (1993) Melatonin: a potent, endogenous hydroxyl radical scavenger. Endocrine J 1: 57-60.

Tan DX, Manchester LC, Reiter RJ, Plummer BF, Limson J, Weintraub ST, Qi W (2000a) Melatonin directly scavenges hydrogen peroxide: a potentially new metabolic pathway of melatonin. Free Radic Biol Med 29: 11771185.

Tan DX, Manchester LC, Reiter RJ, Qi W, Karbownik M, Calvo JR (2000b) Significance of melatonin in antioxi- dative defense system: reactions and products. Boil Signals Recept 9: 137-149.

Tan DX, Manchester LC, Burkhardt S, Sainz RM, Mayo JC, Kohen R, Shohami E, Huo YS, Hardeland R, Reiter RJ (2001) $\mathrm{N}^{1}$-acetyl-N ${ }^{2}$-formyl-5-methoxykynuramine, a biogenic amine and melatonin metabolite, functions as potent antioxidant. FASEB J 15: 2294-2296.

Tan DX, Manchester LC, Hardeland R, Lopez-Burillo S, Mayo JC, Sainz RM, Reiter RJ (2003) Melatonin: a hormone, a tissue factor, an autocoid, a paracoid and an antioxidant vitamin. J Pineal Res 34: 75-78.

Tan DX, Manchester LC, Terron MP, Flores LJ, Reiter RJ (2007) One molecule, any derivatives: a never-ending interaction of melatonin with reactive oxygen and nitrogen species? J Pineal Res 42: 28-42.

Tomas-Zapico C, Coto-Montes A (2005) A proposed mechanism to explain the stimulatory effect of melatonin on antioxidative enzymes. J Pineal Res 39: 99-104.

Urata Y, Honma S, Goto S, Todoroki S, Iida T, Cho S, Honma K, Kondo T (1999) Melatonin induces gammaglutamylcysteine synthetase mediated by activator protein-1 in human vascular endothelial cells. Free Radic Biol Med 27: 838-847.

Uz T, Manev H (1998) Circadian expression of pineal 5lipoxygenase mRNA. Neuroreport 9: 783-786.

Winiarska K, Fraczyk T, Malinska D, Drozak J, Bryla J (2006) Melatonin mitigates diabetes-induced oxidative stress in rabbits. J Pineal Res 40: 168-176.

Witt-Enderby PA, Bennett J, Jarzynaka MM, Firestine S, Melan MA (2003) Melatonin receptors and their regulation: biochemical and structural mechanisms. Life Sci 72: 2183-2198.

Witt-Enderly PA, Radio NM, Doctor JS, David VL (2006) Therapeutic treatments potentially mediated by melatonin receptors: potential clinical uses in the prevention of osteoporosis, cancer and as an adjuvant therapy. $J$ Pineal Res 41: 297-305.

Wurtman RJ, Axelrod J (1965) The pineal gland. Sci Amer 213: 50-60.

Ximenes VF, Campa A, Catalani LH (2001) The oxidation of indole derivatives catalyzed by horse radish peroxidase is highly chemiluminescent. Arch Biochem Biophys 387: 173-179.

Ximenes VF, Silva SO, Rodrigues MR, Catalani LH, Maghzal GJ, Kettle AJ, Campa A (2005) Superoxide dependent oxidation of melatonin by myeloperoxidase. J Biol Chem 280: 38160-38169.

Zavodnik IB, Lapshima EA, Zavodnik LB, Labieniec M, Bryszewska M, Reiter RJ (2004) Hypochlorous acidinduced oxidative stress in Chinese hamster B14 cells: viability, DNA and protein damage and the protective action of melatonin. Mutat Res 559: 39-48.

Zhang H, Akbar M, Kim HY (1999) Melatonin: an endogenous negative modulator of 12-lipoxygenation in the rat pineal gland. Biochem J 344 (pt 2): 487-493. 